\title{
BIBLIOGRAPHIE
}

Orla-Jensen. The lactic acid bacteria, 1919.

BERGEY. Manual of determinative bacteriology, 1948.

A. W. Stableforth. Bull. Office Int. Epizooties, XXX, 121, 1948.

P. Kästrı. Bull. Office Int. Epizooties, XXX, 144, 1948.

H. F. Farrag. Jour. Amer. Vet. Med. Assoc., 371, 1948.

Benson. Jour. Amer. Vet. Med. Assoc., 1948. Ciencia Veterinaria, 1949.

J. P. Marty. La Pénicilline, Vigot Frères, Paris, 1948.

H. KatruchoN et E. G. Hodd. Journal Dairy Science, XXXII, 1949.

Levaditi. Antibiotiques, I. B. Baillière, Paris, 1950.

Aage Jepsen et A. J. Overby. The Nether milk and Dairy Jour., 5, 1951.

R. N. Gostilow et M. L. Speck. Jour. of Dairy Science, XXXIV, 34, 1951.

L. E. Baribo et E. M. Foster. Jour. of Dairy Science, XXXIV, 34, 1951.

Santos Ovejero. Veterinaria, 1951.

S. C. Bryan. Jour, Milk Food Techn., 14, 161, 1951.

W. A. Krienke. Milk Dealer, 104, 1951.

Legislacion (SUecta). Extracto de Le Lait, 307, 1951.

J. Auclatr. Le Lait, XXXI, 121, 1951.

J. Jacquet et P. Julienne. Bull. Acad. Vet., 24, 423, 1951.

K. Е. Тноме́. F.I.L., 1952.

A. Bradfield, L. A. Resi et D. B. Johnstone. Jour. Dairy Science, XXXV, 1952.

R. Willems. Bull. Office Int. Epizooties, XXXVIII, 390, 1952.

Kästl. Extrac. Le Lait, XXXII, 554, 1952.

J. Jacquet, R. Richou, Mc Steeg, C. Gerbaux et P. Julienne. $C$. R. Acad. Sc., 1952.

Santos Ovejero. Rev. Espanola de Lecheria, 5, 273, 1952.

M. M. Lemoine, G. Saucher et H. Girard. Le Lait, XXXIII, 15, 1953.

\section{ESSAIS DE MISE EN CONSERVE DE LAIT ÉCRÉMÉ PAR ENSILAGE (1)}

\author{
par
}

\section{DESOUTTER}

Dans le rapport que j'ai eu l'honneur de vous présenter l'an dernier sur la production laitière en France, j'indiquais que cette production était en augmentation constante, alors que les débouchés étrangers se fermaient à nous, en raison des charges multiples qui pèsent sur nos prix de revient et ne nous permettent pas de lutter à armes égales avec les nations qui nous entourent; et j'ajoutais que la fièvre aphteuse pourrait peut-être ajourner quelque peu une crise vers laquelle nous nous acheminons, mais ne résoudrait pas le problème.

(1) Comptes Rendus de l'Académie Agric., 1953, 39, n० 7, 385. 
Cette épizootie a causé d'énormes dégâts ; en outre la forte sécheresse du printemps et de l'été 1952 a réduit la récolte de fourrage. Et malgré ces deux causes la production laitière est à l'heure actuelle supérieure d'environ $10 \%$ à celle de l'époque correspondante de 1952 .

D'autre part, de très fâcheuses importations de produits laitiers, réalisées à contretemps, ont encore accentué l'encombrement du marché. Si bien que le mois de février a été très mauvais pour ce marché et que l'inquiétude règne, tant dans les milieux de la production que dans ceux de la transformation.

De plus, il résulte de renseignements puisés auprès des commerçants et des bouchers en province que, dans de nombreuses régions laitières, on n'abat guère, en fait de veaux, que des mâles : la plupart des veaux-génisses sont conservés pour l'élevage et seront nourris par les terrains qui produisaient autrefois la nourriture des poulains et des chevaux que le tracteur a fait disparaître.

Nous allons, en conséquence, inéluctablement à une impasse, si des exutoires ne sont pas trouvés aux excédents de lait dont la production est en route.

Naturellement c'est en mai et juin que ces excédents sont les plus importants et les plus encombrants, puisqu'ils coïncident forcément avee la plus forte croissance d'herbe particulièrement nourrissante, et que les animaux en pâture n'ont guère besoin à ce moment d'autre alimentation que cette herbe jeune, tendre et riche.

Ce rapprochement m'a suggéré l'idée de réaliser un stockage de la partie la moins précieuse du lait, e'est-à-dire sa matière protéique ; en un mot, de fabriquer une sorte de fromage de garde pour animaux, puisque les humains n'arrivent plus à consommer toute la production. Le produit obtenu, si l'opération réussissait, devrait fournir un aliment très assimilable.

Pour que cela soit économiquement applicable, il faut, d'une part, qu'il y ait disproportion entre le prix de la caséine et celui des aliments du bétail et, d'autre part, que la mise en conserve du lait écrémé ne nécessite que des frais infimes. Ceci exclut, avec les prix actuls, la possibilité de passer par le stade de la caséine en poudre, à cause des frais de dessiccation.

Je résolus donc de tenter la conservation du lait écrémé par ensilage avec du fourrage vert. Je précise qu'il ne s'agit pas en l'occurence d'employer le lait écrémé comme conservateur du fourrage ensilê ; c'est plutôt le contraire que je voulais réaliser, le fourrage servant en quelque sorte de conservateur-support au lait écrémé.

Une foule de questions se posa aussitôt. Les animaux appré- 
cieraient-ils cette $401^{\mathrm{e}}$ variété de fromages (puisqu'il en existe paraît-il 400 , destinées à la consommation humaine) ? Quels animaux l'apprécieraient? Les pores, les bovins, les volailles ? Ne faudrait-il pas les habituer petit à petit à cet aliment? A quelle concentration, si j'ose employer ce terme pour indiquer la proportion du lait par rapport au volume du fourrage, l'accepteraient-ils ? L'accepteraient-ils seulement jeune, e'est-à-dire après un ou deux mois de fabrication? Mais alors la méthode perdrait son intérêt, le décalage entre production et consommation étant insuffisant. Ou bien l'accepteraient-ils encore en novembre, en janvier et même au mois de mars suivant, c'est-à-dire fortement passé, après neuf mois de fabrication? Ne sentira-t-il pas trop fort?

Il fallait donc réaliser toute une gamme de concentrations et faire en sorte que les échantillons soient répartis dans les silos de manière que leur consommation soit échelonnée jusqu'en mars. D'où l'obligation de tenter l'essai sur un litrage important. Il était d'autre part, de la plus élémentaire prudence de prévoir l'échec et de faire en sorte que cet échec n'entraîne pas la perte d'une quantité de fourrage assez importante pour compromettre le ravitaillement d'hiver du cheptel, sans parler des finances de l'exploitation.

Le chiffre de 200.000 litres de lait écrémé me parut répondre à toutes ces conditions, et devoir permettre en cas de réussite, de réaliser à plein l'application de la méthode dès le printemps 1953 .

Pour passer à la réalisation, la première question qui se posa fut la suivante : fallait-il verser le lait liquide sur le fourrage vert dans les silos, ou le transformer d'abord en caillebotte?

C'est à la seconde solution que je m'arrêtai pour plusieurs raisons :

10 Pour disposer d'un tonnage de lait écrémé assez important, il faut parfois en faire venir d'assez loin ; et pour réduire les frais, il fallait transporter le minimum de liquide, e'est-ă-dire la caillebotte sans le sérum ;

$2^{\circ}$ Comme à cette époque il fait en général très chaud, le lait écrémé liquide coagulerait tout seul et pourrait renfermer des masses de ferments putrides ou butyriques, car naturellement il ne pouvait être question de le pasteuriser, en raison du coût élevé de la pasteurisation.

Prenant done le lait écrémé au sortir de l'écrémeuse, je profitai, par raison d'économie, de ce qu'il était encore chaud pour l'ensemencer avec du sérum, encore chaud lui aussi, de fromages pasteurisés et réensemencé avec des ferments lactiques purs. Apportant ainsi une grande masse de levain lactique pur, j'empêchais le déve- 
loppement des ferments putrides et butyriques. Après eoagulation, découpage et égouttage du caillé, je le conservai, plongé dans du sérum acide, jusqu'au moment de l'emploi.

Tout ceci peut se faire à très bon compte.

Enfin l'ensilage fut réalisé par mélange de la caillebotte avec le fourrage vert au fur et à mesure du remplissage des silos, avec les essais de concentrations suivantes :

50 kilogrammes de caillebotte par mètre cube de fourrage ;

100 kilogrammes de caillebotte par mètre cube de fourrage ;

150 kilogrammes de caillebotte par mètre cube de fourrage ;

200 kilogramme de caillebotte par mètre cube de fourrage ;

250 kilogrammes de caillebotte par mètre cube de fourrage.

Et le tout fut copieusement arrosé avec le conservateur constitué par du sérum de fromages pasteurisés et réensemencé avec des ferments lactiques thermophiles, pour qu'ils résistent à la température élevée du silo. La caillebotte fut en général émiettée. Néanmoins un essai fut aussi réalisé sans émiettage, mais par simple addition d'une masse compacte de caillebotte au milieu du fourrage, pour voir, d'une part, s'il valait la peine d'employer un homme à émietter soigneusement le tout et, d'autre part, si la distribution de la caillebotte ainsi conservée n'en serait pas facilitée.

La précaution fut prise, par raison d'économie, de ne mettre de la caillebotte ni sur le fond du silo, ni contre les parois, ni près de la surface supérieure, e'est-à-dire aux endroits où peuvent se produire quelques pertes. Et le tout fut tassé énergiquement comme pour l'ensilage simple...

Le résultat est tout à fait encourageant et la réussite semble très facile. Tout s'est passé comme s'il n'y avait pas eu de caillebotte mélangée au fourrage, et tant vaut l'ensilage, tant vaut cette espèce de fromage.

D'autre part, les bovins, comme les porcs, l'ont parfaitement accepté d'emblée. Il est vrai que je les avais habitués au silage ordinaire. Ils le mangent aussi volontiers au mois de mars, qu'en janvier ou en novembre et s'en trouvent très bien.

J'ai fait analyser des morceaux de caillebotte ainsi ensilée. C'est de la caséine à peu près pure, comme il était prévu.

La méthode ainsi décrite pourrait présenter un léger inconvévénient : comme j'ajoutais une masse considérable de sérum à la caillebotte en guise de conservateur, ce sérum donne, avec la chlorophylle, qui suinte par tassement du fourrage, une grande quantité de jus. Pour éviter la perte de ce jus, j'ai mélangé dans le bas du silo et en proportion décroissante à partir du bas jusque vers la moitié, des balles de céréales, des barbes d'orges, etc., avec le 
fourrage. Ces menues pailles ont parfaitement absorbé et épongé le jus. J'en ai réglé l'apport de façon à avoir simplement un léger écoulement de jus pour contrôler que toute la masse était bien imbibée. Les animaux ont parfaitement mangé le tout, y compris, quoique moins volontiers, les barbes d'orges qui étaient ainsi ramollies et inoffensives.

Ce dernier procédé peut naturellement, et à plus forte raison être utilisé dans l'ensilage ordinaire sans caillebotte. Il permet d'éviter la perte d'un jus très riche en éléments nutritifs, qui, en s'accumulant en bas du silo, risquerait en outre, s'il ne peut s'écouler, d'abîmer le fourrage qui s'y trouve.

Ce mode d'utilisation du lait de printemps n'a pas la prétention de résoudre à lui seul la crise qui s'annonce. Il n'est susceptible de se développer qu'au fur et à mesure de la généralisation de l'ensilage et dans les régions laitières.

Il est probable que, pour résoudre la crise, il faudra trouver un certain nombre de solutions partielles. Néanmoins celle-ci présente l'intérêt, en même temps que de résorber une partie des excédents difficilement vendables au printemps, d'éviter par la suite, dans la même proportion, des achats onéreux d'aliments du bétail à l'étranger, et, partant, d'être susceptible de contribuer à l'amélioration de notre balance commerciale.

\title{
SUPPLEMENT TECHNIQUE
}

\section{LE PLANNING DANS L'INDUSTRIE LAITIÈRE}

\author{
par \\ G. GÉNIN \\ Ingénieur E.P.C.
}

L'industrie laitière ne fait pas exception à la règle et il importe, dans les exploitations qui utilisent le lait comme matière première, d'apporter à l'organisation du travail, à la direction financière et administrative, à la surveillance des stocks de matières premières ou de produits fabriqués, aux contrôles et aux vérifications de toutes sortes l'esprit méthodique qui s'impose dans tout établissement industriel.

Il est intéressant de voir d'ailleurs comment l'organisation du travail, dans une exploitation laitière, peut être réalisée, en passant successivement en revue les différents secteurs d'une telle exploitation. Hans Pirner, directeur d'une laiterie de Nuremberg, a exposé 